\title{
Knowledge and Health Care Seeking Behaviour About Neonatal Danger Signs Among Mothers Visiting Immunization Unit in Public Health Facilities of Debre Markos Town Northwest Ethiopia, June 2016
}

\author{
Habtamu Chanie (BSc, MSc) \\ Department of Midwifery, College of Medicine and Health Sciences, Debre Markos University, Ethiopia
}

\begin{abstract}
Background: Worldwide the average neonatal mortality was estimated to be 33 per 1000 live births. It is estimated that each year four million neonatal deaths occur, and almost exclusively in low income countries. Danger signs in the neonatal period are nonspecific and can be a manifestation of almost any newborn disease. One of the component in reducing the newborn morbidity and mortality is early recognition of sick newborn and the danger signs of illness and initiation of prompt treatment.

Objective: To assess knowledge and health care seeking behaviour about neonatal danger signs among mothers visiting immunization unit in Public Health Facilities of Debre Markos Town 2016.

Method: A facility based cross sectional study will be employed to assess knowledge and health care seeking behaviour of mothers about neonatal danger signs among mothers visiting immunization unit in public health facilities of Debre Markos, North Waste Ethiopia. Quantitative method of data collection will be deployed by using pre-tested structured interviewer administered questionnaire from a sample of 285 respondents. Systematic random sampling techniques were employed to select mothers with less than 1 year old infant.

Result: From the total respondents, about 197(69.1\%) mothers knew at least one neonatal danger signs. The most common mentioned neonatal danger signs were persistent vomiting, 133(70.7\%), difficulty of breathing $132(69.8 \%)$, diarrhea $127(67.6 \%)$, and fever 124(66.0\%).Only 35(18.6\%), 26(9.7\%), 8(2.9\%) and 7(2.60\%) identified pus discharge from umbilicus, hypothermia (decrease temperature), lethargy/unconsciousness and convulsions as neonatal danger signs respectively.

Conclusion and Recommendation: Most of the mothers were knowledgeable about neonatal danger signs. but, the rest who had no awareness and health care seeking practice should be addressed through maternal and child health services by designing an appropriate strategies including provision of targeted information, education and communication.
\end{abstract}

Keywords: Knowledge, Health care seeking behavior, Neonatal danger signs

DOI: $10.7176 / \mathrm{JMPB} / 52-05$

\section{INTRODUCTION}

Worldwide the average neonatal mortality is estimated to be 33 per 1000 live births. It is estimated that each year four million neonatal deaths occur, and almost exclusively in low income countries [1]. Three quarters of neonatal deaths occur in the first week of life, suggesting the need for early care [2]. Neonatal mortality now accounts for about two-thirds of global infant ( $0-1$ year) mortality and about 3.8 million of the 8.8 million annual deaths of children under five [3].

Over the past several decades, the global incidence of child mortality has steadily decreased.

More than $40 \%$ of under-five deaths now occur in the first month of life - the neonatal period; thus, achievement of Millennium Development Goal 4 (MDG-4) for child survival depends on more effectively addressing neonatal deaths, particularly early deaths in the first week of life. Despite the progress made worldwide in newborn survival, the speed is low in developing countries where the burden of neonatal death accounted for $99 \%$ of all deaths $[4,5]$.

Ethiopia has managed to reduce child mortality by $67 \%$ in the year 2012 and already achieved the Millennium Development Goal (MDG) for child mortality three years ahead of schedule [6]. But still neonatal morbidity and mortality rates in Ethiopia remains among the highest in the world and stem from a range of socio-economic, political and demographic factors. Many of these deaths are preventable. Around 120,000 newborns die every year and the neonatal mortality rate is 37 per 1000 live births [7]. Childhood mortality levels are decreasing in Ethiopia. According to Ethiopian Demographic Health Survey (EDHS 2011), Neonatal Mortality Rate (NMR) is rate 37 per 1,000 live births. Infant mortality Rate (IMR) is 59 deaths per 1,000 live births for the five year before the survey compared with 77 deaths per 1,000 live births in 2005. Under-five mortality levels have also decreased from 123 deaths per 1,000 live births in 2005 to the current level of 88 deaths per 1,000 live births [8].

The newborn cannot explain or express their discomfort and therefore identification and diagnosis of illness may be delayed if parents are not intelligent, observant, and concerned [9]. Mothers are the primary caregivers of the newborn. Thus the knowledge of the mothers regarding newborn danger signs has a great influence on the 
health of the newborn [10].

Integrated Management of Newborn and Childhood Illnesses IMNCI emphasize on mothers, community leaders and health workers to identify danger signs among newborns for early referral to appropriate health care provider/ facility. Early identification with prompt and appropriate referral serves as backbone of the programs aiming at reduction in neonatal mortality [11].

Absence of health care seeking and late seeking are associated with numerous infant deaths in developing countries. In these countries, easily treatable diseases like pneumonia and diarrhea are still the principal causes of illness and death among children under one year of age [12].

In order to achieve the intended goals on promotion of neonatal health and reduction of infant mortality at global, regional and national levels, it is important to study distribution of neonatal illnesses, Care-seeking Behavior, and direct enabling and disabling factors related to health systems which affect neonatal health [13].

Studies from developing countries have reported that delay in seeking appropriate care and not seeking any care contributes to the large number of child deaths [14]. Mothers need to know the danger signs of sick newborn. They can explain these signs to others or family member in a simple language so as to enable them to identify the danger signs and to seek early and prompt medical help. Hence, this study will be carried out to assess mothers' knowledge and health care seeking behavior about neonatal danger signs.

The greatest gap in newborn care is often during the critical first week of life when most neonatal deaths often occur at home and without any contact with the formal health sector. These conditions can be managed if mothers are aware of newborn danger signs and develop experience of early recognition and health care seeking behavior for newborn illness.

This study will assess knowledge of mothers about newborn danger signs and their health care seeking behavior. The results of the study will be used as base line information to design

appropriate policies, strategies, and intervention, which can improve mothers' early recognition of newborn danger signs and their health care seeking behavior and support the maternal and child health service improvement.

This study will contribute for the achievement of globally and nationally intended strategies and programs that promotes neonatal health and reduces infant mortality.

The results of the study will also add the evidence about mother's recognition of newborn danger signs and give background information for further studies in neonatal health and newborn survival.

\section{OBJECTIVES}

\subsection{General objective:}

To assess knowledge and health care seeking behaviour about neonatal danger signs among mothers visiting immunization unit in public health facilities of Debre Markos town 2016.

\subsection{Specific objectives:}

$>$ To describe knowledge of mothers about neonatal danger signs.

To assess health care seeking behaviour of mothers on neonatal danger signs.

\section{METHODS.}

\subsection{Study area and period}

The study will be conducted from June 2016 to September 2016 in public health facilities of Debre Markos town which is located at $299 \mathrm{Km}$ Northwest of Addis Ababa and $265 \mathrm{Km}$ Southeast of the Regional capital city, Bahir Dar. The town is divided in to seven kebeles. The town has 107, 254 total population size of which $52.1 \%$ are females. Out of the total females, $44.9 \%$ are in the reproductive age group and the numbers of households in the town are estimated to be 14,528 . The town has one Referral Hospital, four Health centres, and two none governmental organizations (NGOs) clinics (Marie stops international clinics and family guidance association clinic (FGA)).

\subsection{Study Design}

A facility based cross sectional study design.

\subsection{Population and sample}

\subsubsection{Source population:}

The source population will be all mothers who had children age less than one year and who are attending public health facilities of Debre Markos town for immunization purpose.

\subsubsection{Study population}

The Study population will be all mothers who had children aged less than one year and who are attending health facility for immunization during data collection period in public health facilities of Debre Markos town. 


\subsection{Inclusion and Exclusion criterion}

\subsubsection{Inclusive criteria}

Those mothers who had children aged less than one year and who are attending health facility for immunization during data collection period in public health facilities of Debre Markos town will be included.

3.4.2 Exclusive criteria

* If the infant brought by another person rather than the mother

\subsection{Sample size determination and sampling technique:}

\subsubsection{Sample size determination:}

The sample size (n) size is determined using single population proportion formula by considering the following assumptions: $95 \%$ confidence level, proportion (p) from finding $77.1 \%$ of mothers knew at least one neonatal danger sign from previous study [15] and 5\% marginal error.

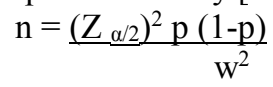

Where $\mathrm{n}=$ minimum sample size required for the study

$Z=$ standard normal distribution $(Z=1.96)$ with confidence interval of $95 \%$ and $\alpha=0.05$

$\mathrm{P}=$ prevalence/ population proportion $(\mathrm{p}=0.771)$

$\mathrm{w}=$ is a tolerable margin of error $(\mathrm{w}=0.05)$

$$
\mathbf{n}=\frac{(1.96)^{2}(0.771)(1-0.771)}{(0.05)^{2}}
$$

$\mathrm{n}=\mathbf{2 7 1}$

For possible none response during the survey the final sample size is increase by $5 \%$ to $n=271+5 \%$ which is $13.5=\mathbf{2 8 5}$

\subsubsection{Sampling procedure}

All governmental public health facilities in Debre Markos town will be included. The desired number of clients will be determined based on the amount of patient of flow in each health facilities using proportional allocation. Study participants will be selected by using systematic random sampling will be used to select the mothers that will be interviewed and the first mothers will be selected by lottery method. The data will be collected from Debre marekos referral hospital, hedasa HC, Debre markos HC, Westa HC, Gozamin HC

$\mathrm{N}$ in health centre $=\mathrm{NF}^{*}{ }_{\mathrm{N}}$ in health centre

$$
\mathrm{N}_{\text {total }}
$$

Where: $\mathrm{n}$ in health center= proportion of mothers in a given health center

$\mathrm{N}$-total $=$ total number of mothers in the selected health centers

$\mathrm{NF}=$ Total sample size

$\mathrm{N}$ in a health center= average number of patient flow in immunization clinic in a given Health center.

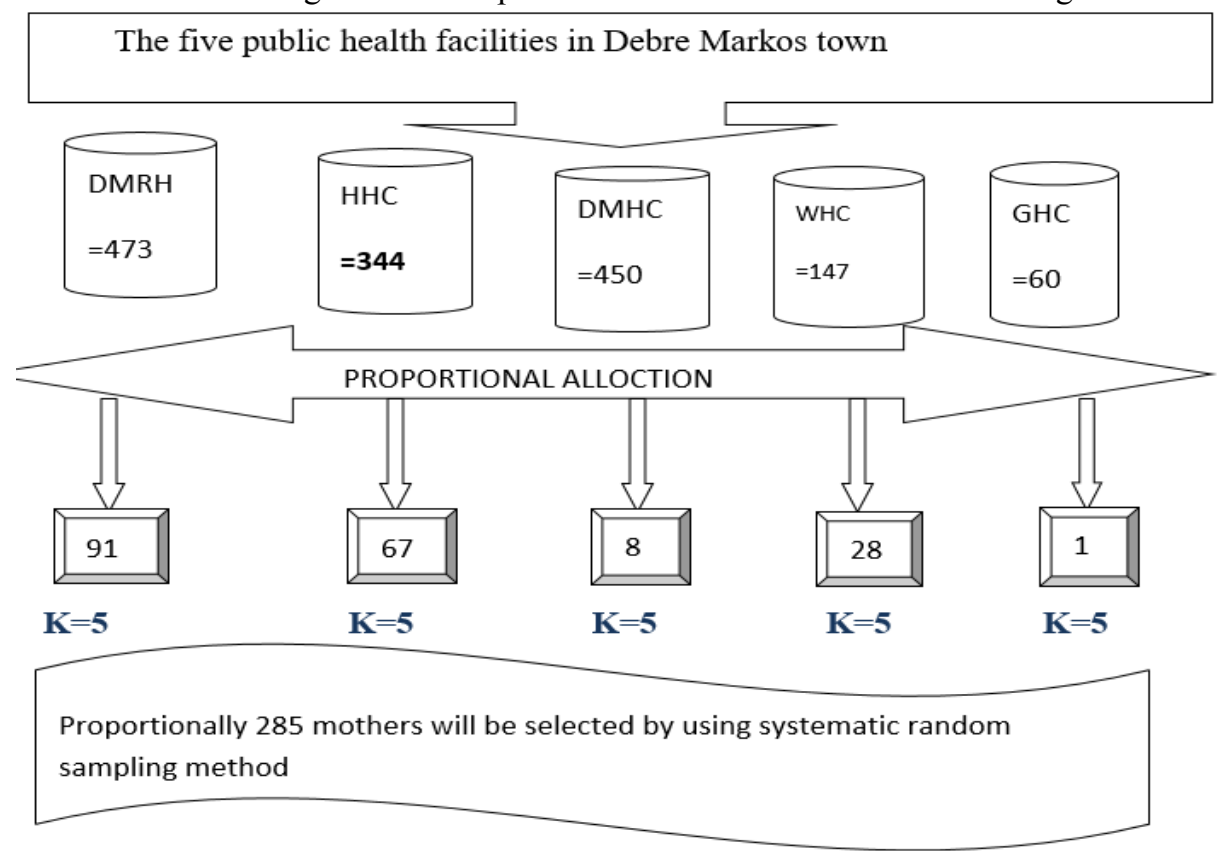




\subsection{Study variables:}

\subsubsection{Dependent variable}

* Knowledge about neonatal danger sign.

* Health care seeking behaviour.

\subsubsection{Independent variable}

* Socio demographic(Age of mother, Age of child, Marital status, Ethnicity, Occupation, Religion, Mother educational level, Father educational level, Income, Number of children, Distance from the health center, Decision making ability, Perceived ability of health professionals, Place of delivery, Time of stay in hospital after deliver

\subsubsection{Operational Definition and definitions}

* Neonatal danger signs: refer to the presence of clinical signs that would indicate high risk of neonatal morbidity and the need for early therapeutic intervention.

* Health Care Seeking Behavior: is defined as any action undertaken by individuals who perceive they have a health problem for the purpose of finding an appropriate remedy and identify the danger sign for appropriate intervention.

\# Highly Knowledgeable: mothers those who answered more than $80 \%$ of the knowledge questions.

* Moderate knowledgeable: mothers those who answered between $55 \%-79.9 \%$ of the knowledge questions.

\# Poor knowledgeable: mothers those who answered $<55 \%$ of the knowledge questions.

\subsection{Data collection instrument and procedures.}

\subsubsection{Data collection instrument:}

Structured interviewer administered questionnaire was used to collect the data which is adapted from relevant literatures and modified to local context in such a way that all the variables to be assessed was included. Questionnaires was translated in to Amharic (official working language) by an individual who are native of both languages then retranslated back to English by other individual to check for any inconsistencies.

\subsubsection{Data collection method:}

Quantitative method of data collection was deployed. Structured interviewer administered questionnaire was used for data collection purposes.

\subsubsection{Data collectors:}

The data collectors were the investigators. In addition, to handle any problem, ensure data quality, and check proper completeness of questionnaire, the supervisors were also investigators.

\subsubsection{Data quality control}

Questionnaires were prepared first in English by the Investigator and then translated in to Amharic. The questionnaire was translated back to English in order to maintain its consistency. The instrument was pretested before actual period of data collection. The Investigators collected the data. The investigators were supervised on daily basis for completeness and consistence of the filled questionnaires. During analysis, data was checked carefully.

3.7.6 Data processing and analysis:

Data was analyzed by Statistical Package for Social Sciences (SPSS) program version 16.0 software, using scientific calculator and MS excel. Different frequency tables, graphs and descriptive summaries were used to describe the study variables.

\subsubsection{Ethical Consideration}

Letter of permission was obtained from research committee of Debre Markos University faculty of medicine health sciences. A formal letter from Debre Markos University was submitted to Debre Markos town health office and concerned bodies to obtain their co-operation. Then permission and support letter was written to DMRH and the four health centres in Debre Markos town. The purpose of the study was explained to the study subjects. At the time of data collection, a verbal consent was taken from the participants to confirm whether they are willing to participate. Those not willing to participate were given the right to do so. Confidentiality of responses was also ensured throughout the research process.

\section{Chapter Four: Result}

A total of 285 mothers were included in this study making a response rate of $100 \%$. Table 1 shows the sociodemographic characteristics of respondents. Accordingly, majority of respondents were $113(39.6 \%)$ in age range of 25-29 and the age of infants was $99(34.7 \%)$ in range of 1-8 weeks. Majority of the respondents accounting for $280(98.2 \%)$ were Amhara by ethnicity, 276(96.8\%) orthodox, 285(100\%) currently in marital union, 144(50.5\%) were house wife, $112(39.3 \%)$ were grade nine to twelve. Regarding, father's educational level majority 106(37.2\%) was above twelve. Out of the total respondents $186(65.3 \%)$ had a monthly income of above 1500 Birr. Regarding number of children majority of the respondents $240(84.2 \%)$ had one to three children (see table 1$)$ 
Table 1: Distribution of socio demographic characteristics of mothers in public health facilities of Debre markos town, East Gojjam Zone, Northwest, Ethiopia, 2016.

\begin{tabular}{|c|c|c|c|}
\hline Variables & Response & Frequency & Percentage \\
\hline Address & Town & 219 & 76.8 \\
\hline & Rural & 66 & 23.2 \\
\hline & Total & 285 & 100.0 \\
\hline Age of mother & $15-19$ & 10 & 3.5 \\
\hline & $20-24$ & 86 & 30.2 \\
\hline & $25-29$ & 113 & 39.6 \\
\hline & $30-34$ & 51 & 17.9 \\
\hline & $35-39$ & 21 & 7.4 \\
\hline & $>=40$ & 4 & 1.4 \\
\hline & Total & 285 & 100. \\
\hline & $<1$ & 43 & 15.1 \\
\hline Age of & $1-8$ & 99 & 34.7 \\
\hline infant(wks) & $9-16$ & 91 & 31.9 \\
\hline & $17-24$ & 16 & 5.6 \\
\hline & $25-32$ & 10 & 3.5 \\
\hline & $33-40$ & 26 & 9.1 \\
\hline & Total & 285 & 100.0 \\
\hline Religion & Orthodox & 276 & 96.8 \\
\hline & Protestant & 6 & 2.1 \\
\hline & Muslim & 3 & 1.1 \\
\hline & Total & 285 & 100 \\
\hline Ethnicity & Amhara & 280 & 98.2 \\
\hline & Tigray & 4 & 1.4 \\
\hline & Oromo & 1 & 0.4 \\
\hline & Total & 285 & 100 \\
\hline educational & Can't write and read & 45 & 15.8 \\
\hline level & Can write and read & 36 & 12.6 \\
\hline & Primary $(1-8)$ & 41 & 14.4 \\
\hline & Secondary $(9-12)$ & 112 & 39.3 \\
\hline & Tertiary(above 12) & 51 & 17.9 \\
\hline & Total & 285 & 100.0 \\
\hline Educational level of & Can't write and read & 19 & 6.7 \\
\hline husband & Can write and read & 51 & 17.9 \\
\hline & Primary $(1-8)$ & 81 & 28.4 \\
\hline & Secondary $(9-12)$ & 28 & 9.8 \\
\hline & Tertiary(above 12) & 106 & 37.2 \\
\hline & Total & 285 & 100.0 \\
\hline Occupation of the mother & Government employed & 76 & 26.7 \\
\hline & Self employed & 28 & 9.8 \\
\hline & Student & 5 & 1.8 \\
\hline & Merchant & 26 & 9.1 \\
\hline & House wife & 144 & 50.5 \\
\hline & Farmer & 6 & 2.1 \\
\hline & Total & 285 & 100.0 \\
\hline Monthly income & Below 200 & 16 & 5.6 \\
\hline & $201-500$ & 29 & 10.2 \\
\hline & $501-1000$ & 32 & 11.2 \\
\hline & $1001-1500$ & 22 & 7.7 \\
\hline & Above 1500 & 186 & 65.3 \\
\hline & Total & 285 & 100.0 \\
\hline Family size & $1-3$ & 240 & 84.2 \\
\hline & $4-6$ & 44 & 15.4 \\
\hline & $7-9$ & 1 & 0.4 \\
\hline & $>9$ & 0 & 0 \\
\hline & Total & 285 & 100.0 \\
\hline
\end{tabular}




\section{Knowledge about neonatal danger sign}

From the total respondents, about 197(69.1\%) mothers knew at least one neonatal danger signs. The most common mentioned neonatal danger signs were persistent vomiting, 133(70.7\%), difficulty of breathing $132(69.8 \%)$, diarrhea 127(67.6\%), and fever 124(66.0\%).Only 35(18.6\%), 26(9.7\%), 8(2.9\%) and 7(2.60\%) identified pus discharge from umbilicus, hypothermia (decrease temperature), lethargy/unconsciousness and convulsions as neonatal danger signs respectively. (See table 2)

Table 2: Recognition of neonatal danger signs of mothers in public health facilities of, Debre markos town, East Gojjam Zone, Northwest, Ethiopia, 2016.

\begin{tabular}{|l|l|l|l|}
\hline Variables & Response & Frequency & Percentage \\
\hline Knowledge about danger signs & Yes & 197 & 69.1 \\
\cline { 2 - 4 } & No & 88 & 30.9 \\
\cline { 2 - 4 } & Total & 285 & 100.0 \\
\cline { 2 - 4 } & Persistent vomiting & 133 & 67.5 \\
\cline { 2 - 4 } & Difficulty of breathing & 132 & 67.0 \\
\cline { 2 - 4 } & Diarrhea & 127 & 64.5 \\
\cline { 2 - 4 } & High grade fever & 124 & 62.9 \\
\cline { 2 - 4 } & Continuous crying & 72 & 36.6 \\
\cline { 2 - 4 } & Poor feeding/unable to suck & 54 & 27.4 \\
\cline { 2 - 4 } & Pus/discharge from umbilicus & 35 & 17.8 \\
\cline { 2 - 4 } & Unable to pass stool & 29 & 14.7 \\
\cline { 2 - 3 } & Baby too cold & 26 & 13.2 \\
\cline { 2 - 3 } & Unable to pass urine & 13.2 \\
\cline { 2 - 3 } & Yellow skin colour(jaundice) & 13 & 6.6 \\
\cline { 2 - 3 } & Red/discharge from eyes & 9 & 4.6 \\
\cline { 2 - 3 } & Lethargy/unconscious & 8 & 4.0 \\
\cline { 2 - 3 } & Convulsion & 7 & 3.6 \\
\hline
\end{tabular}

Of the total respondents who recognize at least one neonatal danger signs, the major Source of information $116(59.0 \%)$ was health professionals, and followed by media, $37(18.8 \%)$.

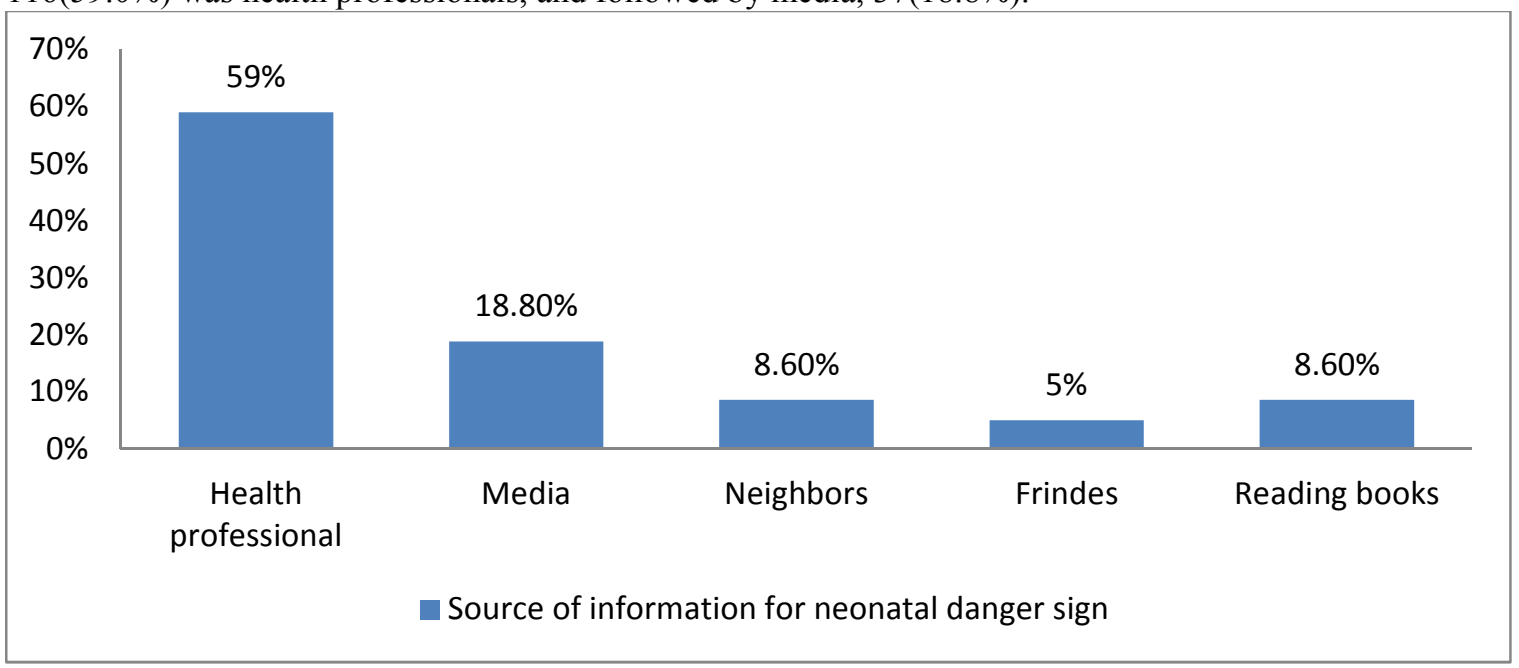

Figure 1: source of information for neonatal danger signs of mothers in public health facilities of Debre markos town, East Gojjam Zone, northwest, Ethiopia, 2016.

Majority of mothers $195(68.5 \%)$ responded that the cause of neonatal illness was poor hygiene and followed by $44(15.4 \%$ ) lack of breast feeding. (See table 3 )

Table 3: Response of Cause of Neonatal Illness of Mothers in public health facilities of Debre markos town, East Gojjam Zone, northwest, Ethiopia, 2016.

\begin{tabular}{|l|l|l|l|}
\hline Variables & Response & Frequency & Percentage (\%) \\
\hline Cause of neonatal illness & Poor hygiene & 195 & 68.5 \\
\cline { 2 - 4 } & Poor feeding & 44 & 15.4 \\
\cline { 2 - 4 } & Exposure to cold/wind & 30 & 10.5 \\
\cline { 2 - 4 } & Don't know & 11 & 3.9 \\
\cline { 2 - 4 } & Evil spirit & 5 & 1.8 \\
\cline { 2 - 4 } & Total & 285 & 100.0 \\
\hline
\end{tabular}


Most common way to identify poor feeding $172(60.4 \%)$ was unable to suck. Seventy one $(26.4 \%)$ respondents did not mention any signs of lethargic/unconsciousness. Regarding fever 115(40.4\%) appreciate the presence of fever by touching forehead. Regarding action for diarrhea about 165(57.9\%) of mothers mentioned take to health facility. Most of the respondents 102(35.8\%) did not know signs of unable to pass stool/constipation. Most of the study participants $96(33.7 \%$ ) did not know signs of breathing problems in neonates. Out of the total participants 279(97.9\%) knew the importance of the continuing breast feeding for Sick neonate. About 279(97.9\%) respondent's feed first milk (colostrums) to their neonates. (See table 4)

Table 4: Response of Mothers on signs of neonatal danger sign in public health facilities of Debre markos town, East Gojjam Zone, northwest, Ethiopia, 2016.

\begin{tabular}{|c|c|c|c|}
\hline Variables & Response & Frequency & Percentage $(\%)$ \\
\hline \multirow[t]{7}{*}{ Sign of improper breast feeding } & unable to suck & 172 & 60.4 \\
\hline & unable to swallow & 22 & 7.7 \\
\hline & Breast engorgement & 25 & 8.8 \\
\hline & Sucking long time & 13 & 4.6 \\
\hline & Don't know & 31 & 10.9 \\
\hline & crying & 22 & 7.7 \\
\hline & Total & 285 & 100.0 \\
\hline \multirow[t]{7}{*}{ Sign of lethargic neonate } & no energy & 104 & 36.5 \\
\hline & Weakness & 36 & 12.6 \\
\hline & sleep long time & 24 & 8.4 \\
\hline & unable to wake for feeding & 31 & 10.9 \\
\hline & Don't know & 71 & 24.9 \\
\hline & unable to breast feed & 19 & 6.7 \\
\hline & Total & 285 & 100.0 \\
\hline \multirow[t]{6}{*}{ Sign of neonatal fever } & Hot to touch forehead & 115 & 40.4 \\
\hline & Hot to touch body & 113 & 39.6 \\
\hline & Sweating & 22 & 7.7 \\
\hline & don't know & 25 & 8.8 \\
\hline & Irritable & 10 & 3.6 \\
\hline & Total & 285 & 100.0 \\
\hline \multirow[t]{6}{*}{ Managementof diarrhea } & Increase breast feeding & 27 & 9.5 \\
\hline & Give LEMLEM/ORS & 49 & 17.2 \\
\hline & $\begin{array}{l}\text { Take to health } \\
\text { institution }\end{array}$ & 165 & 57.9 \\
\hline & Don't know & 34 & 11.2 \\
\hline & do nothing & 10 & 3.5 \\
\hline & Total & 285 & 100.0 \\
\hline \multirow[t]{8}{*}{ Sign of constipation } & Don't know & 102 & 35.8 \\
\hline & Pain during defecation & 54 & 18.9 \\
\hline & Hard stool & 46 & 16.1 \\
\hline & Irritable /cry & 43 & 15.1 \\
\hline & passes stool less than $3 x$ per week & 33 & 11.6 \\
\hline & Hard abdomen & 5 & 1.8 \\
\hline & blood in stool & 2 & .7 \\
\hline & Total & 285 & 100.0 \\
\hline \multirow[t]{7}{*}{ Sign respiratory system disorder } & I don't know & 96 & 33.7 \\
\hline & Cough & 51 & 17.9 \\
\hline & Grunting & 44 & 15.4 \\
\hline & fast breathing & 43 & 15.1 \\
\hline & stops breathing & 37 & 13.8 \\
\hline & runny nose & 14 & 4.9 \\
\hline & Total & 285 & 100.0 \\
\hline \multirow{3}{*}{$\begin{array}{l}\text { Breast feeding habit sick } \\
\text { neonate }\end{array}$} & Yes & 279 & 97.9 \\
\hline & No & 6 & 2.1 \\
\hline & Total & 285 & 100.0 \\
\hline \multirow[t]{2}{*}{ Reason for not feeding } & Cause vomiting & 4 & 66.65 \\
\hline & Cause diarrhea & 2 & 33.35 \\
\hline
\end{tabular}




\begin{tabular}{|l|l|l|l|}
\hline Variables & Response & Frequency & Percentage (\%) \\
\hline & Total & 6 & 100.0 \\
\hline \multirow{3}{*}{ Habit of colostrums } & Yes & 279 & 97.8 \\
\cline { 2 - 4 } & No & 6 & 2.2 \\
\cline { 2 - 4 } & Total & 285 & 100.00 \\
\hline $\begin{array}{l}\text { Reason for not giving } \\
\text { colostrums }\end{array}$ & It is harmful for a baby & 3 & 50.00 \\
\cline { 2 - 4 } & Prohibited by elderly & 2 & 33.50 \\
\cline { 2 - 4 } & don't know & 1 & 16.50 \\
\cline { 2 - 4 } & Total & 6 & 100.00 \\
\hline
\end{tabular}

\section{Level of knowledge about danger signs of neonate}

According to this study most of respondents about $131(46.0 \%)$ highly knowledgeable, $5(1.7 \%)$ were poor knowledgeable and 61(21.4) were moderate knowledgeable about neonatal danger signs.

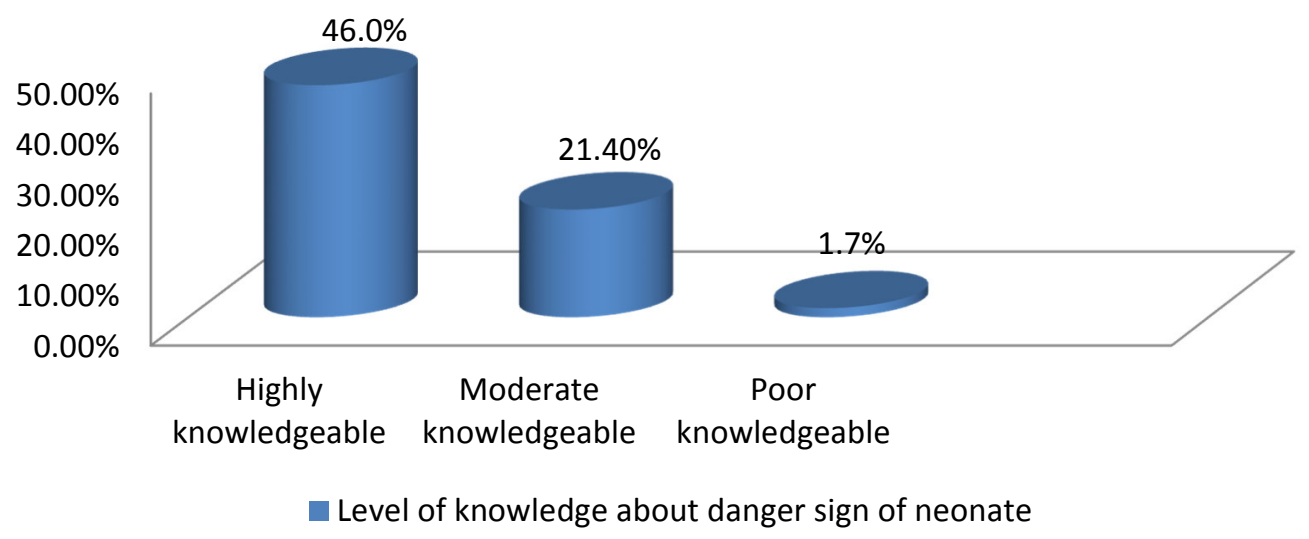

Figure 2: Knowledge level about neonatal danger signs among mothers in public health facilities of Debre markos town, East Gojjam Zone, northwest, Ethiopia, 2016.

\section{Health Care-Seeking for Neonatal Danger Signs}

About $32(11.2 \%)$ of the mothers had seen a sick neonate in their family in the past one year.

And 12(37.5\%) of neonates manifested as fever, 9(28.1\%) diarrhea/loose stools, and 2(6.25\%) cough/ breathing problems. (See table 5)

Table 5: Mothers report on the presentation of danger signs in sick neonate in public health facilities of Debre markos town, East Gojjam Zone, northwest, Ethiopia, 2016..

\begin{tabular}{|l|l|l|l|}
\hline Variables & Response & Frequency & Percentage (\%) \\
\hline $\begin{array}{l}\text { Sick neonate in the } \\
\text { family within the last one }\end{array}$ & Yes & 32 & 11.2 \\
\cline { 2 - 4 } year & No & 253 & 88.8 \\
\cline { 2 - 4 } & Total & 285 & 100.0 \\
\hline \multirow{3}{*}{$\begin{array}{l}\text { Signs of sickness } \\
\text { recognized by mothers }\end{array}$} & Fever & 12 & 37.5 \\
\cline { 2 - 4 } & Diarrhea & 9 & 28.1 \\
\cline { 2 - 4 } & Crying & 3 & 9.4 \\
\cline { 2 - 4 } & Vomiting & 3 & 9.4 \\
\cline { 2 - 4 } & Breathing problems & 2 & 6.2 \\
\cline { 2 - 4 } & Inability to breast feed & 2 & 6.2 \\
\cline { 2 - 4 } & Skin rash/pustule & 1 & 3.1 \\
\hline
\end{tabular}

Health care was sought for $26(81.2 \%)$ neonates. The rest were treated with home treatment, Traditional treatment and do nothing. 


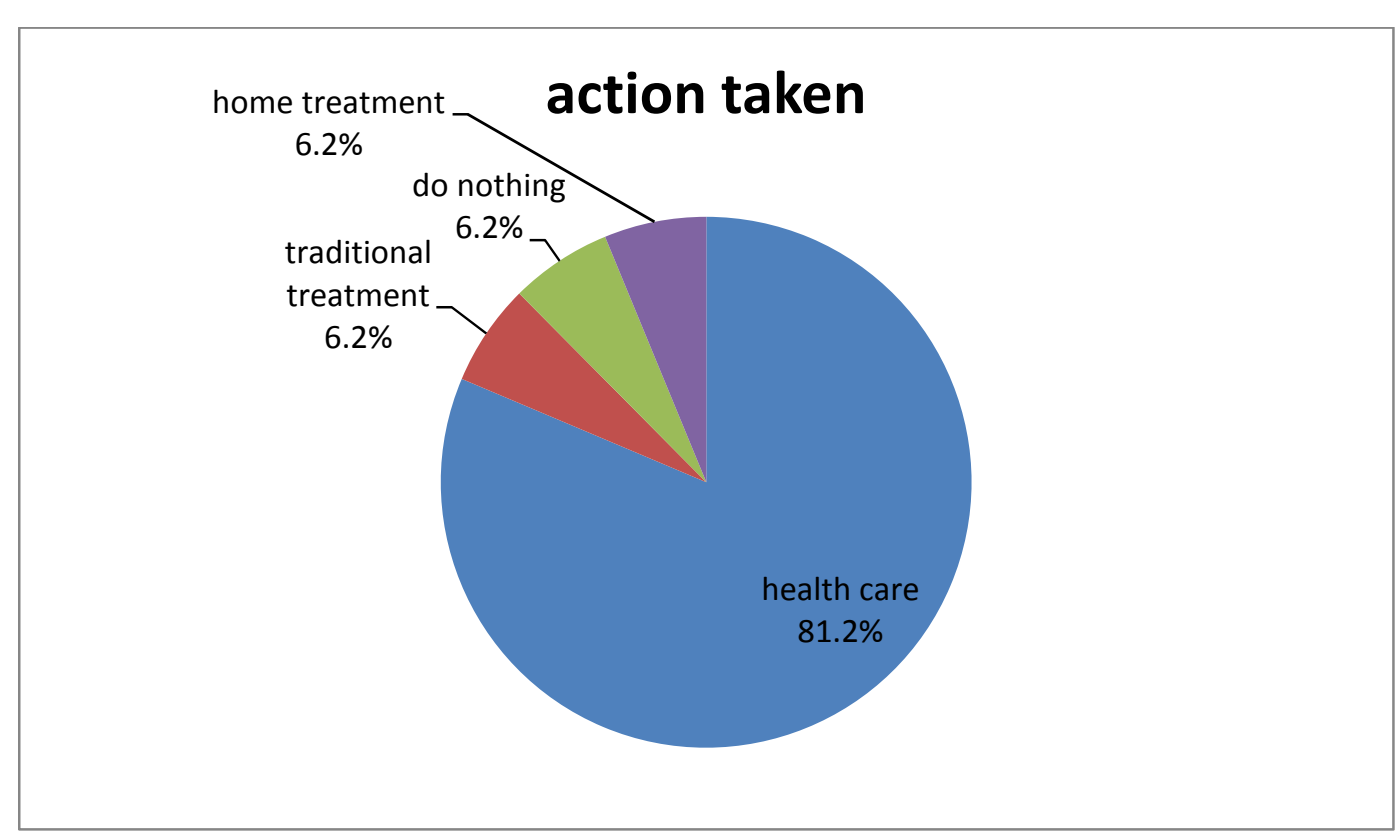

Figure 3: Action taken for sick neonates of mothers in public health facilities of Debre markos town, East Gojjam Zone, northwest, Ethiopia, 2016

Among 32(11.2\%) mothers who sought health care for their sick neonate majority 28(87.5\%) preferred government health centres and followed by $4(12.5 \%)$, private health facilities. Regarding the time taken to seek health care for sick neonate majority $15(46.9 \%)$ of mothers brought their neonate to health facilities within one to four hours after recognition of signs of illness. And others spent five to eight hours, one day, two days, more than two days before seeking health care, $7(21.9 \%), 8(25.0 \%), 1(3.1 \%), 1(3.1 \%)$, respectively.

When we look at reason for delayed health care seeking majority $5(41.7 \%)$ of mothers mentioned the child would be better. Other reasons mentioned include transportation, to Begin with home treatment, it is not sever, lack of awareness, and lack of money.

Table 6: Reason for delay of health care seeking for sick neonate of mothers in public health facilities of Debre markos town, East Gojjam Zone, northwest, Ethiopia, 2016

\begin{tabular}{|l|l|l|l|}
\hline Reason for delayed health care seeking & Responses & Frequencies & Percentage (\%) \\
\cline { 2 - 4 } & Didn't know it is danger sign & 3 & 25 \\
\cline { 2 - 4 } & Health centre is far & 1 & 8.3 \\
\cline { 2 - 4 } & Lacked money & 2 & 16.7 \\
\cline { 2 - 4 } & Get better & 5 & 41.7 \\
\cline { 2 - 4 } & To try home remedies first & 1 & 8.3 \\
\cline { 2 - 4 } & Total & 12 & 100.0 \\
\hline
\end{tabular}

Regarding the mothers perception towards the ability of health professional in neonatal care unit of the health centre, most respondents accounting for 134 (47.0\%) said health professionals were good. (See table 7)

Table 7: Perception of mothers about ability of health professional working in neonatal and child health unit in public health facilities of Debre Markos town, East Gojjam Zone, northwest, Ethiopia, 2016

\begin{tabular}{|l|l|l|l|}
\hline Variables & Response & Frequency & Percentage (\%) \\
\hline Perceived ability of health professionals & Excellent & 26 & 9.1 \\
\cline { 2 - 4 } & Very good & 98 & 34.4 \\
\cline { 2 - 4 } & Good & 134 & 47 \\
\cline { 2 - 4 } & Poor & 21 & 7.4 \\
\cline { 2 - 4 } & No idea & 6 & 2.1 \\
\cline { 2 - 4 } & Total & 285 & 100.0 \\
\hline
\end{tabular}

Out of the total respondents majority $141(52.2 \%)$ of mothers could decide on health care seeking for their sick neonate while 101 (37.5\%) decision could be decided by both mother and fathers. Other said decision could be made by grandparent, neighbours and relatives. 


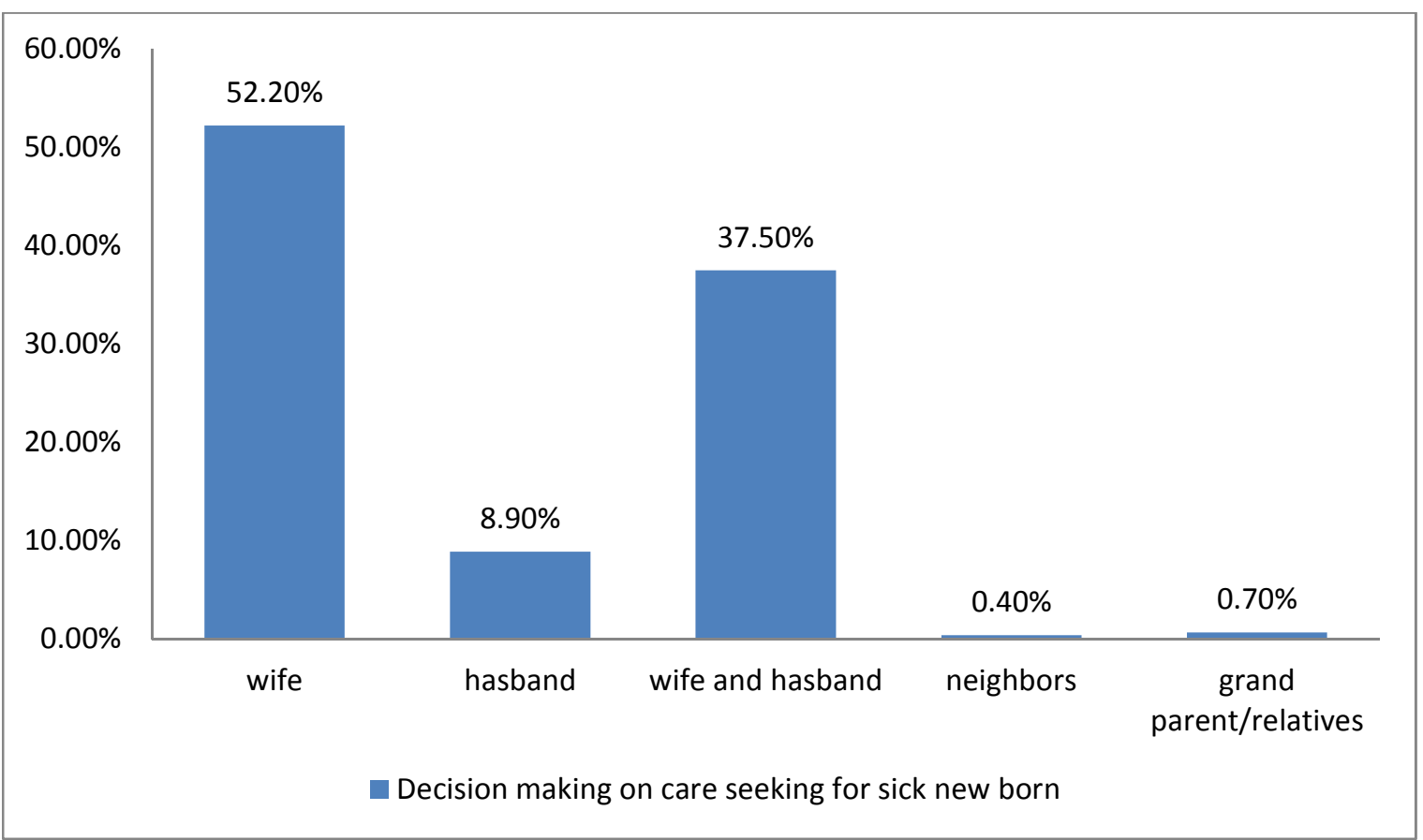

Figure 4: Decision making for sick neonate of mothers in public health facilities of Debre markos town, East Gojjam Zone, northwest, Ethiopia, 2016

\section{Chapter Five: Discussion}

This study tried to assess knowledge and health care seeking behaviour about neonatal danger signs among mothers visited immunization unit in public health facilities of Debre markos town, northwest Ethiopia.

This study showed that about $69.1 \%$ mothers knew at least one neonatal danger sign while $30.9 \%$ of mothers did not know any of the danger signs of neonate. The most common mentioned by mothers who know neonatal danger signs were persistent vomiting $67.5 \%$, difficulty of breathing $67.0 \%$ diarrhea $64.5 \%$, and fever $62.9 \%$. Only few mothers mentioned pus discharge from umbilicus $17.8 \%$, hypothermia (decrease body temperature) $9.7 \%$, lethargy/unconsciousness 4.0 and convulsions $3.6 \%$ as neonatal danger. This finding was comparably less than a study conducted in Addis Ababa, in which $77.1 \%$ of mothers of knew at least one neonatal danger sign [31]. This difference might be due to difference in health intervention activities in the areas. And another study conducted in Peri-Urban Wardha, India $40.3 \%$ mothers identified difficulty in breathing, $22.2 \%$ poor sucking and $13.9 \%$ lethargy/unconsciousness as neonatal danger signs respectively [27]. Only $9.7 \%$ convulsion and $2.8 \%$ hypothermia identified as neonatal danger signs respectively. In both studies few mothers identified convulsions and hypothermia as danger signs of neonate.

In this study, $65.3 \%$ of mothers had mentioned poor hygiene, $15.4 \%$ poor feeding $10.5 \%$ exposure to cold weather/wind and $1.4 \%$ evil spirit/eye as cause of neonate illness while $4.1 \%$ mothers don't know cause of neonatal illness. This finding is different with study conducted in Wardha, India in which almost all the danger signs/symptoms supernatural causes were suspected. This might be socio cultural deference between the study participants.

Result of this study, showed that about $11.2 \%$ of the mothers had seen a sick neonate in their family in the past one year. And $37.5 \%$ of neonates manifested as fever, $28.1 \%$ diarrhea/loose stools, and $6.2 \%$ cough/ breathing problems Health care was sought for $87.5 \%$ neonates. According to study conducted in Addis Ababa $33.3 \%$ of mothers had seen a sick neonate in their family in the past one year, with common manifestation of fever $43 \%$, Diarrhea/loose stools $34.7 \%$, Cough/ breathing problems. And health care was sought for $65.3 \%$ neonates. Similar study conducted in Northern India $39.5 \%$ of care givers seen sick neonate in their family with a common manifestation of fever $72.14 \%$ and only $23 \%$ of mothers sought health care for sick neonates. This study also varies with study conducted in Wardha, India in which $41.8 \%$ of sick neonates got medical treatment. These variations might be explained by differences in the disease spectrum between these different study areas.

Regarding the time taken to seek health care for sick neonate this study showed that $46.9 \%$ of mothers brought their neonate to health facilities within one to four hours after recognition of signs of illness the main reason for delayed health care seeking $41.7 \%$ of mothers mentioned the child would be better. Other reasons mentioned include transportation, to begin with home treatment, it is not sever, lack of awareness, and lack of money. Similar study in Addis Ababa also showed that only $38 \%$ of mothers brought their sick neonate to health facilities within one to four hours after recognition of signs of illness. And the main reason for delayed for 
Health care seeking $49 \%$ of mothers mentioned was thinking the neonate would be better. Other reasons include perception of medication not good for neonate, to start with home treatment, thinking it is not sever, lack of awareness.

According to this study $52.2 \%$ of mothers could decide on health care seeking for their sick

Neonates while $37.55 \%$ by both husband and mother around $8.9 \%$ decision made by father. Other said decision could be made by grandparent/relatives and neighbours. This finding is comparably less with study conduct in Addis Ababa which 68.9\% of mothers could decide on health care seeking for their sick neonates while $15.5 \%$ decision made by father. This was due to the difference in socio demographic status of study areas.

\section{Chapter Six: Conclusion and Recommendation}

\subsection{Conclusion}

Most of the respondents knew at least one danger sign of neonate mainly diarrhea, vomiting and fever but other danger signs like convulsion, pus discharge from umbilicus, hypothermia (decrease body temperature) and lethargy/unconsciousness were not well recognized. Most of the participants were highly knowledgeable about neonatal danger signs. Even though most mothers seek health care for their sick neonates, there were delays in time of health institution visit. And the main reason for delay was thinking the neonate would get better.

\subsection{Recommendation}

* The health zone health Bureau should strengthen regular training for health professionals regarding neonatal danger sign.

* Debre markos town Health Bureau should strengthen health services in improving the information given during Ante natal, postnatal and immunization follow up, with special emphasis given to danger signs of neonate.

\section{AKNOWLEDGENT}

I am grateful to thank Debre Markos town Health Bureau for their collaboration during data collection time. I would like to thank mothers of the study area who were involved in the study.

Last but not least I would like to thank those individuals who contributed directly or indirectly to the successful completion our study.

\section{Competing interests}

The author declares that they have no competing interests

\section{ABBREVIATIONS}

- DMU :Debre markos University

- EDHS: Ethiopia Demographic and Health Survey

- ENC: Essential Newborn Care

- ETB: Ethiopian Birr

- HC: Health Canter

- IMNCI : Integrated Management of Neonatal and Childhood Illness

- IMR : Infant Mortality Rate

- MDG : Millennium Development Goal

- NMR : Neonatal Mortality Rate

- WHO : World Health Organization

\section{Annex: References}

1. Zupan, J., Aahman, E., 2005. Perinatal mortality for the year 2000: estimates developedby WHO. World Health Organization, Geneva. PubMed Abstract | Publisher Full Text

2. Darmstadt, G.L., Hussein, M.H., Winch, P.J., Haws, R.A., Lamia, M., El-Said, M.A., Gipson, R.F., Santosham, M., 2007. Neonatal home care practices in rural Egypt duringthe first week of life. Trop. Med. Int. Health 12, 783-797. PubMed Abstract |Publisher Full Text

3. Lawn JE, Kerber K, Enweronu-Laryea C, Massee Bateman O: Newborn survival in lowresource settingsare we delivering? BJOG 2009, 116:49-59. PubMed Abstract |Publisher Full Text

4. Claeson M, Bos ER, Mawji T, et al. 2000 Reducing child mortality in India in the new millennium. Bull World Health Organ; 78:1192-9. PubMed Abstract | Publisher Full Text

5. Lawn JE, Cousens S, Bhutta ZA, et al. (2004) why are 4 million newborn babies dying each year? Lancet; 364:399-401. PubMed Abstract | Publisher Full Text

6. Child Mortality MDG Success: a signal of transformation from economic growth to development in Ethiopia UNICEF's progress report on child mortality entitled "Committing to Child Survival: By Belayneh Akalu 
09/30/13

7. Lawn JE, Cousens S, Zupan J (2005) 4 million neonatal deaths: when? Where? Why? Lancet 365(9462): 891900. Doi: 10.1016/s0140-6736(05)71048-5. PubMed Abstract |Publisher Full Text

8. Central Statistical Agency [Ethiopia] and ICF International: Ethiopia Demographic and Health Survey 2011. Addis Ababa, Ethiopia and Calverton, Maryland, USA: CentralStatistical Agency and ICF International; 2012.

9. Darmstadt GL, Bhutta ZA, Cousens S, Adam T, and Walker N, de Bernis L: Evidence-based, cost-effective interventions: how many newborn babies can we save? Lancet 2005, 365(9463):977-988. PubMed Abstract | Publisher Full Text

10. Ayekpam Sushila, Margaret Binu E, Shetty Sheela. (2008) A Study to Assess theEffectiveness of an Information Booklet on Newborn Danger Signs Among the AntenatalMothers in Selected Rural Maternity and Child Welfare (RMCW) Centers, UdupiDistrict, Karnataka State Availableat: URL:http://www.indianjournals.com/ijor.aspx?target $=$ ijor:ijone \&volume $=3 \&$ issue $=2 \&$ article $=030$

11. World Health Organization: Technical bases for the WHO recommendations on the management of pneumonia in children at first leve World Health Organization. Counsel the mother: management of childhood illnesses.

12. Jones G, Steketee RW, Black RE, Bhutta ZA, Morris SS; Bellagio Child Survival StudyGroup. How many child deaths can we prevent this year? Lancet 2003; 362:65-71.PubMed Abstract | Publisher Full Text

13. Martines J, Paul VK, Bhutta ZA, Koblinsky M, Soucat A, Walker N, Bahl R, Fogstad H,Costello A: Neonatal survival: a call for action. Lancet 2005, 365(9465):1189-1197.PubMed Abstract | Publisher Full Text

14. Reyes H, Perez-Cuevas R, Salmeron J, Tome P, Guiscafre H, and Gutierrez G: (1997)Infant mortality due to acute respiratory infections: the influence of primary care

15. Gupta $\mathrm{p}$ et al: care seeking behavior of mothers during illness of newborn in urban slums of Lucknow city: Indian journal of community health, vol 24, No.3, July 2012-sep 2012.

16. Universal Journal of Public Health 3(2): 49-54, 2015; Anwar-ul-Haq1, Hameed Mumtaz Durrani2, *, Ramesh Kumar3, Salma Mumtaz Durrani4 I; Recognizing the Danger Signs and Health Seeking Behaviour of Mothers in Childhood Illness in Karachi, Pakistan http://www.hrpub.org; 